\title{
AN EXTRACTOR FOR MOORE'S PINS
}

\section{J. Hutchison, Dundee, Scotland}

Fixation of a slipped upper femoral epiphysis by multiple pins is now generally preferred to that obtained by trifin nail, which is more difficult to place accurately, requires more force to insert, and may be associated with a higher incidence of avascular necrosis (Hall 1957). The only disadvantage of Moore's pins is that they may be difficult to extract when healing is complete. The pin is slender and the outer three-fourths is threaded to accommodate the nut which prevents over-penetration by the pointed end. As healing progresses, the relatively dense spongy bone in the neck of the adolescent femur grows into the grooves of the threads and grips the pin firmly. Subsequent removal is difficult and sometimes impossible with an ordinary chuck-handle. An instrument has therefore been designed which enables a hammer blow to be applied directly in the line of extraction, allowing easy removal of the pins.

The extractor (Fig. 1) consists of a metal rod six millimetres in diameter, one end of which has been drilled and tapped to fit the thread of a Moore's pin. The rod is twenty

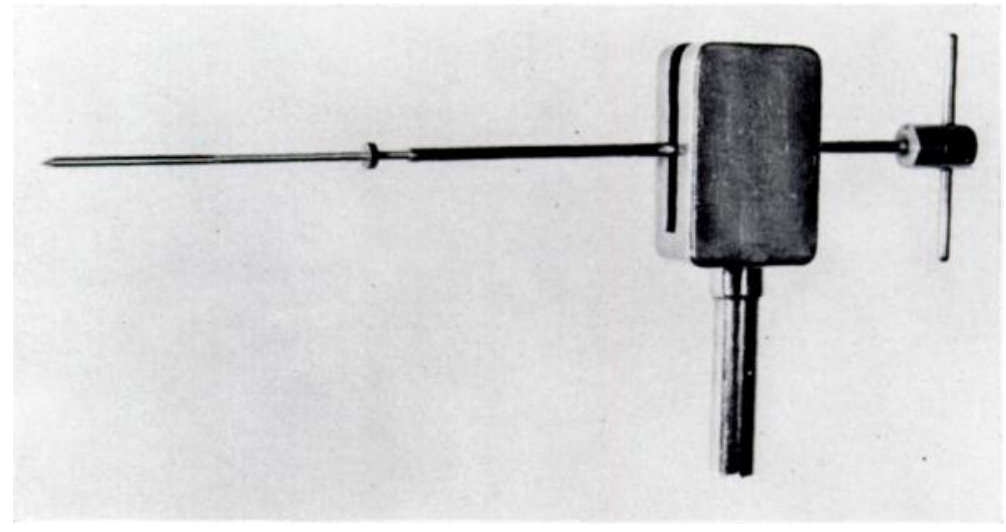

Fig. 1

centimetres long and has a metal flange at the other end with a transverse bar to facilitate screwing the instrument on to the pin. The extractor is more easily engaged if, at the original operation, the excess pin has been cut off cleanly with wire cutters, leaving six or seven millimetres projecting beyond the nut as suggested by Moore (1937). Two sizes of pin are available. It is thus advisable to have two extractors unless the size used is known.

Technique-The ends of the pins are exposed by an incision through the original scar. It is usually necessary to remove the nut before the extractor is applied, but on several occasions it has been possible to screw the instrument on to the pin and remove it with the nut in situ. The slotted hammer, normally used in the extraction of Küntscher nails, is fitted over the shaft of the extractor. A few blows delivered on the flanged end along the shaft suffice to loosen and extract the pin.

I am grateful for the help that I have received from Mr P. Fraser, Senior Technician in the Orthopaedic Workshop, Bridge of Earn Hospital, Perthshire, who made the original instrument.

\section{REFERENCES}

Hall, J. E. (1957): The Results of Treatment of Slipped Femoral Epiphysis. Journal of Bone and Joint Surgery, 39-B, 659.

MOORE, A. T. (1937): Fracture of the Hip Joint. Surgery, Gynecology and Obstetrics, 64, 420. 